Burguet is of more recent origin. It is said to work by " re-educating" the ear by minimal auditory stimuli. As one exponent of the method claims that it acts by producing a local hyperaemia, and another places the lesion in the cerebral cortex and regards it as due to intestinal toxaemia, the rationale of the method is a little difficult to grasp. It is, however, significant that the patient is warned that one or two years' treatment may be needed.

\section{The Need for a Scientific Approach}

At a discussion on this subject at the B.M.A. Meeting in Edinburgh in 1927, Dan McKenzie deplored the attitude of regarding all forms of treatment for otosclerosis as useless, and maintained that we should pass all therapeutic measures under strict scientific examination. Some hints of what members regarded as scientific methods emerged during the discussion. Guthrie, who had seen no conclusive results from the Zund-Burguet method, thought that the mental attitude of both doctor and patient entered very largely into the treatment. Another member of the Section, who said that he would rather lie under the false stigma of quack and charlatan than break his Hippocratic oath to do the best he could for his patients, admitted that in a considerable proportion of his cases treated by this method there was a functional element. Yet another member, after objecting to Jenkins' method of using the term " otosclerosis " so as to include, as he considered, other middle-ear conditions in addition to true otosclerosis, quoted the case of an " otosclerotic" lady who after a course of the Zund-Burguet treatment, had her hearing increased from five to forty-eight feet. "In view of such a case, and it was not unique," the member said he did not consider himself justified in abstaining from giving this treatment in otosclerosis. $\mathrm{He}$ then added that he believed the improvement in the case quoted to have been entirely functional! It is true that " you can perform any miracle if you only make a wrong diagnosis," but the miracle fails to impress when the absurdity of the diagnosis is thus flaunted in our faces. Are we out to compete with the faith cures of the revivalist meeting? Professor Nager, who, like Fraser and many others, had never seen any result from the Zund-Burguet method, touched upon another aspect of the question when he said that he had seen patients coming from the celebrated Coué who were convinced of very marked improvement, though the tuning-fork tests remained unchanged. There is probably no class of patient so ready to believe himself better when he is not than the deaf-perhaps a not unnatural result of the urgent wish. These cases and the hysterical malade imaginaire are the backbone and mainstay of such forms of treatment, each exponent presumably remaining " true to his oath" but not, apparently, obliged to pass his methods under " strict scientific examination."

Gray's treatment by the intratympanic injection of thyroxine was based on the assumption, as yet unproved, that this would produce a local increase in the circulation similar to the general increase seen after its internal administration. This improved local circulation was expected to produce an improvement in the hearing analogous to that seen in his " paradoxica" cases. Only fourteen cases were published, and of these seven were unaffected. In the remaining seven the improvement, though claimed by Gray as great, was well within the limits of variation seen in so many cases of deafness. Apparently no controls were used, and when in one case this was inadvertently present in that the untreated ear showed greater improvement than the one treated, Gray attributed this to a " crossed reflex." Although the treatment was claimed to be the rational outcome of the author's theory of the pathogenesis of otosclerosis, it was described as a treatment for " allied types of deafness" also. These " allied types" appear to be "so-called chronic dry middle-ear catarrh-if such a condition has any real pathological existence." Indeed, a warning was uttered against attempting to differentiate between the two conditions, since it is apparently in the latter type that the greatest improvement was expected. Subsequent investigation has entirely failed to justify Gray's expectations.

Admittedly the problem of otosclerosis is a difficult one. It is not likely to be solved by doubtful diagnosis and still more doubtful observations on the results of treatment.

\section{ESTIMATION OF THE COAGULATION TIME OF THE BLOOD: A SIMPLIFIED METHOD}

\author{
BY \\ H. TROUGHT, B.Sc. \\ AND
}

J. W. RIDDOCH, F.R.C.S.ED.

(Dudley Road Hospital, Birmingham)

Numerous techniques for estimating the coagulation' time of the blood have been devised during recent years, varying from elaborate procedures involving lengthy times of observation and the use of expensive apparatus to the simpler methods employed in the ordinary clinical laboratory. Since the estimation of the coagulation time of the blood is of great importance in the differential diagnosis of various haemorrhagic conditions there is no apology needed, it seems, for the introduction of yet another technique, the ease and simplicity of which serve as its own recommendation.

\section{Apparatus Required}

One glass tube drawn out into a capillary open at both ends is the only essential piece of apparatus. Gross variations in the size of the capillary bore are to be avoided, but the minor variations of capillary tubing drawn out in the ordinary laboratory do not influence the experiments significantly. A filter paper divided by pencil into segments from the centre is required for receiving the drops of blood expelled from the tube. An ordinary watch with a second hand attached can be used for marking the time intervals, but a stop-watch, if available, is more accurate and convenient.

Blood is drawn up into the capillary tube by surface tension, and at minute intervals the end is placed in a slanting direction on to the segments of the filter paper. Before coagulation the drop of blood is absorbed into the filter paper. After an interval varying from five to nine minutes for normal bloods a tiny thread of fibrin stretches out from the filter paper to the end of the capillary tube. The appearance of this thread of fibrin is taken as the coagulation time of the blood in question, and there is no possibility of mistaking the appearance of the fibrin thread in practice, so that uniform results can easily be obtained on repetition.

\section{Experimental Work}

The modified method was tried out in comparison with the well-known standard Wright's capillary tube technique in twenty normal cases and in ten pathological ones. The advantage of the newer method is obvious here in that only one capillary tube is needed instead of the ten or twelve tubes used for Wright's technique.

In the first six of the normal cases variations at three temperatures were observed, and comparison of venous 
and capillary blood coagulation times was made in Wright's method, while the modified method was compared at room temperature only (Table I). Conversely, in the next fourteen of the normal cases Wright's method was estimated at room temperature only, and the newer method was tried out at the three temperatures (Table II) : room temperature (circa $17^{\circ} \mathrm{C}$.) ; $21^{\circ} \mathrm{C}$. (theatre temperature); and $25^{\circ} \mathrm{C}$. For the maintenance of these three temperatures large glass beakers filled with water were placed on hot plates and the temperatures of the water, as registered by thermometers immersed therein, were kept at constant levels by means of the electric regulators together with asbestos mats.

To keep the water from rising in the capillary tubes for Wright's method the ends of the tubes were sealed in a micro-burner before immersion, and for the newer method at the higher temperatures the capillary tube was bent into a "U" shape so that both open ends could be above the surface of the water.

TABLE I.-First Series of Normal Cases

\begin{tabular}{|c|c|c|c|c|c|c|}
\hline \multicolumn{5}{|c|}{ Wright's Method } & \multicolumn{2}{|c|}{ Newer Method } \\
\hline 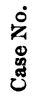 & $\begin{array}{l}\text { Kind of } \\
\text { Blood }\end{array}$ & $\underset{\substack{\text { Room } \\
\text { ture }}}{\text { Tomera }}$ & $25^{\circ} \mathrm{C}$. & $37^{\circ} \mathrm{C}$. & $\underset{\text { Blood }}{\text { Kind of }}$ & $\begin{array}{c}\text { Room } \\
\text { Tempera } \\
\text { ture }\end{array}$ \\
\hline \multirow{3}{*}{1} & & minutes & minutes & minutes & & minutes \\
\hline & / Venous & 9 & 7 & 6 & Venous ... & 8 \\
\hline & Capillary & 8 & 7 & 6 & Capillary... & 7 \\
\hline \multirow{2}{*}{2} & f Venous & 6 & 6 & 5 & Venous ... & 7 \\
\hline & Capillary & 7 & 6 & 5 & Capillary... & 8 \\
\hline \multirow{2}{*}{3} & ;Venous & 8 & 8 & 6 & Venous ... & 8 \\
\hline & lapillary & 8 & 7 & 5 & Capillary... & 7 \\
\hline \multirow{2}{*}{4} & / Venous & 8 & 7 & 6 & Venous ... & 7 \\
\hline & Capillary & 8 & 6 & 5 & Capillary... & 9 \\
\hline \multirow{2}{*}{5} & f Venous & 7 & 5 & 4 & Venous ... & 7 \\
\hline & Capillary & 8 & 6 & 4 & Capillary... & 8 \\
\hline \multirow{2}{*}{6} & / Venous & 7 & 5 & 4 & Venous ... & 7 \\
\hline & I Capillary & 8 & 7 & 5 & Capillary... & 8 \\
\hline
\end{tabular}

TABLE II.-Second Series of Normal Cases

\begin{tabular}{|c|c|c|c|c|c|c|c|}
\hline \multicolumn{5}{|c|}{ Newer Method } & \multicolumn{3}{|c|}{ Wright's Method } \\
\hline $\begin{array}{l}\dot{0} \\
\dot{z} \\
. \\
. \\
.\end{array}$ & $\begin{array}{c}\text { Kind of } \\
\text { Blood }\end{array}$ & $\begin{array}{c}\text { Room } \\
\text { Tempera- } \\
\text { ture }\end{array}$ & $21^{\circ} \mathrm{C}$ & $25^{\circ} \mathrm{C}$ & $\begin{array}{c}\text { Kind of } \\
\text { Blood }\end{array}$ & & $\begin{array}{l}\text { Room } \\
\text { Tempera } \\
\text { ture }\end{array}$ \\
\hline \multirow{3}{*}{1} & & minutes & minutes & minutes & & & minutes \\
\hline & Venous & 8 & 8 & 7 & Venous & & 8 \\
\hline & Capillary & 8 & 5 & 5 & Capillary & & 5 \\
\hline \multirow{2}{*}{2} & Venous & 6 & 5 & 5 & Venous & & 6 \\
\hline & Capil ary & 6 & 5 & 5 & Capillary & & 6 \\
\hline \multirow{2}{*}{3} & (Venous & 6 & 5 & 5 & Venous & & 6 \\
\hline & Capillary & 6 & 6 & 5 & Capillary & & 6 \\
\hline 4 & " & 7 & 6 & 6 & •" & $\ldots$ & 10 \\
\hline 5 & •• & 8 & 8 & 6 & • & $\ldots$ & 8 \\
\hline 6 & " & 13 & 9 & 9 & 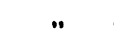 & ... & 10 \\
\hline 7 & .• & 7 & 7 & 6 & & $\ldots$ & 7 \\
\hline 8 & • & 5 & 4 & 3 & " & ... & 5 \\
\hline 9 & .• & $9 \frac{1}{2}$ & 81 & 7 & • & $\ldots$ & 81 \\
\hline 10 & " & 7 & 6 & 6 & . & $\ldots$ & 7 \\
\hline 11 & " & 7 & 6 & 6 & " & $\ldots$ & 7 \\
\hline 12 & " & 10 & 9 & 8 & $"$ & $\ldots$ & 10 \\
\hline 13 & . & 7 & 6 & 6 & & .. & 7 \\
\hline 14 & " & 6 & 6 & 5 & " & $\ldots$ & 6 \\
\hline
\end{tabular}

From an analysis of the six cases of the first series we see verified the already recognized fact of the decrease of coagulation time with rise in temperature.

This stresses the need for knowledge of the temperature conditions of the experiment. However, from consideration of the second series, we see that four or five degrees difference in temperature is necessary before the result is altered outside the limits of ex-

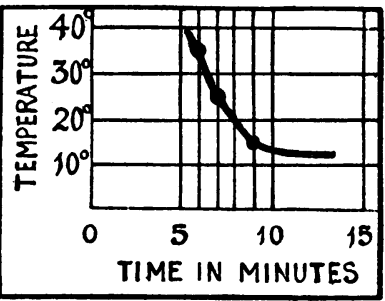
perimental error. Thus in

the second series in only two cases does the raising of the room temperature to $21^{\circ} \mathrm{C}$. produce an alteration of more than one minute in the coagulation time. This fact is valuable from the point of view of estimating coagulation times in surgical procedures, when it may be convenient to do tests in the operating theatre itself, the temperature of which is usually about $21^{\circ} \mathrm{C}$. The results of such tests will clearly be comparable with the results of tests done at other times in the out-patient room or at the patient's bedside. Furthermore, in seventeen of the tests made above the new method agrees with Wright's method either identically or with only a difference of one minute, which must be considered to be definitely within the limits of experimental error. For the other three tests the variation is less than a pathological difference would be.

TABLE III.-Pathological Cases (at Room Temperature)

\begin{tabular}{c|c|c||c|c|c}
\hline Condition & $\begin{array}{c}\text { Wright's } \\
\text { Method }\end{array}$ & $\begin{array}{c}\text { Newer } \\
\text { Method }\end{array}$ & Condition & $\begin{array}{c}\text { Wright's } \\
\text { Method }\end{array}$ & $\begin{array}{c}\text { New. r } \\
\text { Metho. }\end{array}$ \\
\cline { 2 - 3 } minutes & mins. & minutes & mins. \\
Purpura & 15 & 15 & Jaundice & 11 & 12 \\
$\begin{array}{c}\text { Reputed } \\
\text { hannophilia } \\
\text { Jaundice }\end{array}$ & 6 & 6 & Jaundice & 11 & 13 \\
$\begin{array}{c}\text { Hodgkin's } \\
\text { disease }\end{array}$ & 8 & 8 & Epistaxis bruising & 8 & 7 \\
Jaundice & 10 & 10 & Jaun qice & 9 & 10 \\
\hline
\end{tabular}

\section{Summary}

An extremely simple modified method of estimating the coagulation time of the blood has been demonstrated; one which is easy of application and capable of yielding reliable results in the hands of an experienced technician.

According to R. BACHRACH (Wien. klin. Woch., September 11 th, 1936, p. 1123) infection of the urinary tract by Entamoeba histolytica is a rare finding. Posner first reported a case in a German in 1893. Of amoebic cystitis Panojataton has reported seven cases in Egypt, and Franchini ten from Bologna, including some in which there was no evidence of intestinal infection. The mode of infection of the urinary passages is usually by urethrovesical extension in women, but is haematogenous or lymphogenous in man. The clinical features were unspecific - chiefly haematuria, dysuria, and secondary renal symptoms: cystoscopic findings have included ulceration and cyst formation and have sometimes been negative. Bachrach describes a case of amoebic urinary infection in a European from Shanghai who showed cystoscopically a vesicle papillomatosis and in whom the urinary sediment contained numerous amoebae as well as gonococci : after treatment by emetine for fourteen days the parasites disappeared from the urine and the papillomata were excised. Death occurred eventually from pyelonephritis and was preceded by reappearance of the amoeba in the urine. Amoebae had also been detected in the excised papillomata lying encysted between the epithelial cells. Bladder papillomata, not uncommon in chronic bilharziasis, have not hitherto been reported in amoebic infections. 